\title{
Enhancing Doctor-Patient Communication Using Email: A Pilot Study
}

\author{
Shou Ling Leong, MD, Dennis Gingrich, MD, Peter R. Lewis, MD, \\ David T. Mauger, PhD, and John H. George, PhD
}

Background: The doctor-patient relationship has been eroded by many factors. Would e-mail enhance communication and address some of the barriers inherent to our medical practices?

Methods: Of our study population, 4 physicians offered e-mail communication to participating patients and 4 did not. Both patients and physicians completed questionnaires regarding satisfaction, perceived quality, convenience, and promptness of the communication.

Results: Patient satisfaction significantly increased in the e-mail group compared with the control group in the areas of convenience $(P<.0001)$ and the amount of time spent contacting their physician $(P<.0001)$. Physician satisfaction in the e-mail group increased regarding convenience, amount of time spent on messages, and volume of messages. The response time was longer with e-mail. When asked if patients should be able to e-mail their physicians, most patients in the e-mail group and all but 2 of the physicians in the non-e-mail group responded "yes."

Conclusion: E-mail communication was found to be a more convenient form of communication. Satisfaction by both patients and physicians improved in the e-mail group. The volume of messages and the time spent answering messages for the e-mail group physicians was not increased. E-mail has the potential to improve the doctor-patient relationship as a result of better communication.(J Am Board Fam Pract 2005;18:180-8.)

Effective communication between patients and doctors has always been the hallmark of a mutually beneficial doctor-patient relationship, contributing to improved clinical outcomes and high rates of patient and physician satisfaction. New technology can dramatically change that communication, from the invention of the telephone in 1876 to the more recent electronic mail (e-mail). These technologies revolutionize doctor and patient contact, with potential benefits tempered by concerns including privacy, security, and unwanted daily intrusions. ${ }^{1,2}$

Submitted, revised, 23 December 2004.

From the Departments of Family and Community Medicine (SLL, DG, PRL, JHG) and Health Evaluation Sciences (DTM), Penn State College of Medicine, Hershey. Address correspondence to Shou Ling Leong, MD, Penn State College of Medicine, Penn State Milton S. Hershey Medical Center, PO Box 850, Hershey, PA 17033-0850 (e-mail: sleong@psu.edu).

This research was supported in part by a General Clinical Research Center grant from National Institutes of Health (M01-RR10732) awarded to the Pennsylvania State University College of Medicine and the Penn State Milton S. Hershey Medical Center.

This work has been presented at the 36th Society of Teachers of Family Medicine Annual Spring Conference; 2004 Sep 20-24; Atlanta, Georgia, and the 31st Annual North American Primary Care Research Group; 2003 Oct 25-28; Banff, Alberta, Canada.
Internet use is increasing dramatically and many individuals are using e-mail to communicate with family or friends about health issues. ${ }^{3-5}$ In one study by Neill et al, $85 \%$ of patients believed e-mail "would be a good way for a patient to communicate with his/her physician." ${ }^{6}$ Another study suggested that roughly one half of the patients in 2 large primary care centers used e-mail, but only $10.5 \%$ had ever used e-mail to communicate with a physician. ${ }^{7}$ However, $70 \%$ of these patients indicated a willingness to use e-mail communication with their physician. In a survey of primary care physicians in Boston, $75 \%$ of physicians reported using e-mail with patients, but only with a small subset (5\% or less) of their overall patient population. ${ }^{8}$

When patients e-mail their physicians, the purpose is primarily for prescription refills, nonurgent consultations, and to obtain laboratory test results. ${ }^{9}$ Physicians' responses to these e-mail communications range from no reply to providing detailed information. ${ }^{10}$ This emerging technology, with its variable application to and impact on the doctorpatient relationship, has prompted the American Medical Association to produce the "Guidelines for Patient-Physician Electronic Mail."11 
Benefits and risks associated with using e-mail communication have been identified. ${ }^{12-19}$ Rapid, inexpensive, simple, convenient, and asynchronous communication are distinct benefits that could result in a reduction in the number of nonurgent telephone calls to the office, an increase in patient participation in medical decision-making, and an improved linkage to patient education materials. ${ }^{20}$ Concerns about privacy and security, inappropriate use for acute serious illnesses, potential for increased physician workload, and legal liability are serious limitations. Physician concerns regarding time consumption, however, may be overstated. ${ }^{21,22}$ Patient concerns regarding e-mail communication include routing the message to the right person, length of time for a response, and privacy issues. $^{7}$

Despite these concerns, e-mail communication between patients and their physicians is likely to increase and may result in a reconfiguration of physician office function. ${ }^{23-26}$ Therefore, further assessment of patient and physician satisfaction with e-mail communication is indicated. In this article, we report on a 6-month assessment of patient and physician e-mail communication focusing on the following aspects of this interaction:

- Patient and physician satisfaction

- Perception of convenience

- Turnaround time for physician response

- Volume of messages received from patients

- Types of messages

- Physician time requirement to address messages

\section{Methods}

\section{Study Population}

This Institutional Review Board-approved study was conducted from December 2001 to July 2002 in a faculty-based clinic affiliated with The Penn State Milton S. Hershey Medical Center. The majority of the practice's patients come from middleto upper-income communities with high employment rates. Almost all patients have health insurance, including 24\% Medicare and 3\% Medical Assistance. Only $3 \%$ of the patient population have no insurance. Eight family physicians agreed to participate in the study. The investigator assigned the physicians into one of 2 groups: the intervention group, which offered e-mail communication to patients, and the control group, which did not. This
Table 1. Selected Characteristics of Participating Physicians at Baseline

\begin{tabular}{lcc}
\hline Categories & $\begin{array}{c}\text { E-mail } \\
\text { Group }\end{array}$ & $\begin{array}{c}\text { Control } \\
\text { Group }\end{array}$ \\
\hline Age (years) & & \\
$\quad 30$ to 49 & 2 & 2 \\
50 to 65 & 2 & 2 \\
Sex & & \\
$\quad$ Female & 1 & 2 \\
$\quad$ Male & 3 & 2 \\
Average number of years in practice & 15.3 & 21.3 \\
Use e-mail daily & $100 \%$ & $50 \%$ \\
Use e-mail 2 times per week & $0 \%$ & $50 \%$ \\
"I find it easy to use e-mail" & & \\
$\quad$ Agree to strongly agree & $100 \%$ & $50 \%$ \\
Geriatric Practice & $50 \%$ & $50 \%$ \\
"I would consider communicating via & & \\
$\quad$ e-mail with patients" & & \\
$\quad$ Yes & 1 & 1 \\
$\quad$ Not sure & 3 & 3 \\
\hline
\end{tabular}

assignment was used to achieve a comparable profile for the 2 groups in terms of physician age, sex, and attitude toward offering e-mail access to patients, as well as age of patient population (Table 1).

\section{Recruitment}

The inclusion criteria for patients were regular use of e-mail and an existing doctor-patient relationship with one of the participating physicians. During the enrollment period, the office nurses screened all patients who came in for a scheduled appointment with 1 of the 8 participating physicians. The screening consisted of the nurses' asking whether the patient used e-mail regularly. Patients who said yes were then asked whether they were regular patients of the participating physicians. The nurses also review the patients' medical records to confirm that they have seen the physician at least 3 times in the past. Those patients identified as regular patients of the participating physicians and that use e-mail regularly were offered an opportunity to participate in the study. Consented patients of doctors in the intervention group were given their physician's e-mail address for communication. $\mathrm{Pa}$ tients of physicians in the control group were not given e-mail access.

\section{Procedure}

A separate e-mail account was established for each of the 4 physicians in the e-mail group following 
pre-existing guidelines for doctor-patient e-mail at the Hershey Medical Center. These guidelines were adopted from a white paper by Kane on "Guidelines for the Clinical Use of Electronic Mail with Patients." 23 Patients were advised not to use e-mail for emergency or urgent matters that could not wait 3 to 5 days, or issues they felt were sensitive/confidential. An auto-reply feature informed patients of the receipt of their message or if the physician was away for an extended period of time. The e-mail system used for this study was set up by the information technology department specifically for this study and was established within a secure server. Patients in both the e-mail and control group were referred to the patient education web site, http://www.familydoctor.org, created by the American Academy of Family Physicians for health and drug information.

During office hours, clinic secretaries recorded all phone calls from patients to the e-mail and control group physicians on standard message slips. Using these message slips, the physicians recorded their responses to patients, which were later filed in the patients' records. For data analysis purposes, a copy of all patient messages was collected over a week at baseline and 3 selected weeks during the 6-month study period for data analysis. Phone messages received after normal hours were not tracked. E-mail messages were automatically recorded electronically, and copies of the initial message, physician reply, and subsequent communications (if any) were filed into the patients' charts. During the 3 selected weeks, all physicians completed a time log and recorded the number of messages received and time spent in answering patient messages each day. All participating patients and physicians completed satisfaction questionnaires at the onset of the study and at the 3-month and 6-month intervals.

\section{Survey Instrument}

On the patient questionnaire, participants were asked their age, sex, number of years in the practice, level of education, and comfort and frequency of e-mail usage. Patients were also asked whether they used the Internet for various purposes, including locating health information. In part 2 of the patient questionnaire, patients were asked to rank on a 5 -point Likert scale their satisfaction regarding ease and convenience of communication with their physician, promptness of the reply, quality and amount of information in the reply, and the quality of home care instruction they received. They also were asked to rank the health information web site in terms of usefulness and frequency of use. On the physician questionnaire, the physicians were asked similar questions, except that in part 2, they were asked to rank their satisfaction with the practice's message system overall and the amount of time to reply to messages, their promptness in responding to messages, volume of messages, convenience of the system, quality of the messages, and the amount of patient education offered. Both patients and physicians were asked whether patients should be able to e-mail their physicians and whether e-mail should be used for prescription refills and scheduling appointments. Participants in both the e-mail and control groups completed their respective patient or physician questionnaires.

\section{Analysis}

Patient and physician responses to questionnaires were summarized by frequency tables for categorical responses and descriptive statistics for continuous responses. Changes in the level of patient satisfaction across time were assessed within each group using the Friedman test for ordinal responses and repeated measures analysis of variance for continuous responses. Differences between the study and control groups with respect to patient satisfaction were assessed using analysis of variance controlling for physician effects. Given the few physicians in the study, changes in the level of physician satisfaction across time were not statistically significant. However, these data provided some general observations on physician response to e-mail communication with patients. Statistical analyses for other outcome measures were descriptive in nature. These data included the number of messages received, time physicians spent on answering messages, types (categories) of messages received, and response time (time lapse between when a message was received and when the physician replied). The response time and categories of messages were generated for both e-mail and phone messages. All analyses were conducted using SAS statistical software version 8.0 (SAS Institute, Cary, NC).

\section{Results}

Of 172 registered participants, 100 patients (58\%) completed all questionnaires and were included in 
the data analyses (67 in the e-mail group, and 33 in the control group). All 8 physicians completed their time logs and questionnaires.

\section{Patient Profile}

The patient characteristics for both e-mail and control groups were similar (Table 2). The e-mail group was slightly younger, with $42 \%$ under age 50 vs $21 \%$ in the control group. There was equal distribution for the age-group older than 65 and for sex. On average, patients had been in the practice for more than 8 years. Three quarters of the patients had completed at least a college education. Most found it easy to use e-mail, and nearly 50\% spent 1 to 10 hours per week on the computer.

Table 2. Selected Characteristics of Participating Patients at Baseline

\begin{tabular}{|c|c|c|c|c|}
\hline \multirow[b]{2}{*}{ Categories } & \multicolumn{2}{|c|}{$\begin{array}{c}\text { E-Mail } \\
\text { Group } \\
(\mathrm{N}=67)\end{array}$} & \multicolumn{2}{|c|}{$\begin{array}{l}\text { Control } \\
\text { Group } \\
(\mathrm{N}=33)\end{array}$} \\
\hline & $\mathrm{N}$ & $\%$ & $\mathrm{~N}$ & $\%$ \\
\hline \multicolumn{5}{|l|}{ Age (years) } \\
\hline 30 to 49 & 12 & 41.8 & 7 & 21.2 \\
\hline 50 to 65 & 17 & 35.8 & 19 & 57.6 \\
\hline$>65$ & 38 & 22.4 & 7 & 21.2 \\
\hline \multicolumn{5}{|l|}{ Sex } \\
\hline Female & 33 & 49.3 & 18 & 54.5 \\
\hline Male & 29 & 43.3 & 14 & 42.4 \\
\hline Missing data & 5 & & 1 & \\
\hline Average number of years in practice & 8.6 & & 11.3 & \\
\hline \multicolumn{5}{|l|}{ Highest level of education completed } \\
\hline High School & 17 & 25.4 & 6 & 18.2 \\
\hline College & 23 & 34.3 & 14 & 42.4 \\
\hline Graduate School & 26 & 38.8 & 12 & 36.4 \\
\hline Missing data & 1 & & 1 & \\
\hline \multicolumn{5}{|l|}{ I find it easy to use e-mail } \\
\hline Agree to strongly agree & 58 & 86.5 & 29 & 87.9 \\
\hline \multicolumn{5}{|l|}{$\begin{array}{l}\text { The number of hours spent using } \\
\text { my computer each week }\end{array}$} \\
\hline$<1$ hour & 4 & 6 & 0 & 0 \\
\hline 1 to 10 hours & 33 & 49.3 & 16 & 48.5 \\
\hline 10 to 20 hours & 12 & 17.9 & 5 & 15.2 \\
\hline$>20$ hours & 18 & 26.8 & 11 & 33.3 \\
\hline Missing data & & & 1 & \\
\hline \multicolumn{5}{|l|}{ Use internet for* } \\
\hline Health information & 47 & 58 & 23 & 69.7 \\
\hline Entertainment & 26 & 32.1 & 16 & 48.5 \\
\hline News & 42 & 31.9 & 23 & 69.7 \\
\hline Business/finance & 36 & 44.4 & 19 & 57.6 \\
\hline Shopping & 37 & 45.7 & 17 & 51.5 \\
\hline
\end{tabular}

* Responses are not mutually exclusive.
They used the Internet for health information (58\% e-mail group, $70 \%$ control group), entertainment (32\% e-mail, $49 \%$ control), news (32\% email, 70\% control), business/finance (44\% e-mail, $58 \%$ control), and shopping (46\% e-mail, $52 \%$ control).

\section{Satisfaction}

Patients

Patients in this study were generally very satisfied with the communication with their doctors at the time of entry into the study, rating most items in the questionnaire 4 or higher on a 5 -point scale. However, 2 items showed a statistically significant difference between groups during the study. The level of satisfaction significantly increased in the e-mail group, compared with the control group in the areas of convenience of communicating with their physician $(F=8.29 ; P<.0001)$, as shown in Figure 1, and the amount of time spent contacting their physician $(F=7.84 ; P<.0001)$, Figure 2 .

\section{Physicians}

Physicians in both the e-mail and the control groups were generally dissatisfied with the practice's message system, rating it less than 3 on a 5 -point scale. Given the few physicians in the study, changes in the level of physician satisfaction across time were not statistically significant; there were, however, some notable trends that seemed to correlate with the patients' responses. Over the 6-month study period, physicians in the e-mail group seemed to have increased their satisfaction ratings in the message system in the areas of convenience, amount of time spent on messages, and volume of messages. They consistently rated their satisfaction higher than the non-e-mail physician group. These possible trends could be better studied using a larger physician sample. There were no significant changes in the number of messages during the study between the 2 groups either by selfreporting $(F=0.65 ; P=.42$ ) (Table 3 ) or by the data gathered by the clinic secretaries $(F=2.71$; $P=.10)$. This suggests that perhaps the increased satisfaction may be the result of improved convenience or quality of communicating with patients.

\section{Messages}

During the 3 selected weeks when all phone messages were collected for the study, 732 messages with complete information were available for data 
Table 3. Physician Self-Reported Log on Non-E-Mail and E-mail Messages from Patients

\begin{tabular}{|c|c|c|c|c|c|c|c|c|c|c|c|}
\hline \multirow[b]{2}{*}{ Log Entries } & \multicolumn{6}{|c|}{ E-mail Physician } & \multicolumn{5}{|c|}{ Control Physician } \\
\hline & Week & E-1 & $\mathrm{E}-2$ & $\mathrm{E}-3$ & E-4 & Average & $\mathrm{C}-1$ & $\mathrm{C}-2$ & $\mathrm{C}-3$ & C-4 & Average \\
\hline \multirow[t]{3}{*}{ Number of non-e-mail messages } & 1 & 15 & 41 & 79 & 51 & & 52 & & 33 & 72 & \\
\hline & 2 & 46 & 47 & 80 & 60 & & 45 & 28 & 31 & 52 & \\
\hline & 3 & 32 & 28 & 103 & 31 & & 21 & & 57 & & \\
\hline Average & & 31 & 38.6 & 87.3 & 47.3 & 51.1 & 39.3 & & 40.3 & & \\
\hline \multirow{3}{*}{$\begin{array}{l}\text { Average time/day spent addressing messages } \\
\quad \text { (in minutes) }\end{array}$} & 1 & 11 & 29 & 36.2 & 60 & & 20 & 27.4 & 28 & 85 & \\
\hline & 2 & 15 & 35 & 63.4 & 56 & & 20.4 & 19 & 29.2 & 50 & \\
\hline & 3 & 10 & 29 & 40.6 & 62 & & 7.6 & 8.7 & 55 & 50 & \\
\hline Average & & 12 & 31 & 46.7 & 59.3 & 37.3 & 22.5 & 18.3 & 37.4 & 61.7 & 35 \\
\hline \multirow[t]{3}{*}{ Average time per message (in minutes) } & 1 & 3.7 & 3.5 & 2.3 & 5.9 & & 1.9 & 2.8 & 4.2 & 5.9 & \\
\hline & 2 & 1.6 & 3.7 & 3.9 & 4.7 & & 2.3 & 3.4 & 4.7 & 5.0 & \\
\hline & 3 & 1.56 & 5.1 & 1.9 & 6.0 & & 1.8 & & 4.8 & 3.8 & \\
\hline Average & & 2.3 & 4.1 & 2.7 & 5.5 & 3.7 & 2.0 & & 4.6 & 4.9 & 3.8 \\
\hline Number of e-mails in 6 months & & 80 & 121 & 28 & 70 & & & & & & \\
\hline Number of e-mails per week & & 0 to 1 & 1 to 4 & 0 to 5 & 0 to 1 & & & & & & \\
\hline Approximate time per e-mail (in minutes) & & 1 to 3 & 1 to 3 & 1 to 2 & 1 to 5 & & & & & & \\
\hline
\end{tabular}

analyses (329 from the e-mail group and 406 from the control group). Over the study period, 299 emails were received from patients in the e-mail group. For all messages, we analyzed the categories, response time, and time required to address messages.

\section{Categories}

Of the phone messages, $270(37 \%)$ were in the categories of administrative (referral, forms com- pletion), 199 (27\%) were on questions related to medical condition/consult, and 145 (20\%) were on issues related to medications (refill, side effects, instruction on taking medication). A smaller number of messages were related to test results and/or were informational (update of conditions, sharing of information) (Table 4). E-mail messages included 95 (32\%) informational, 93 (31\%) on medical conditions/consult, 48 (16\%) on medication,

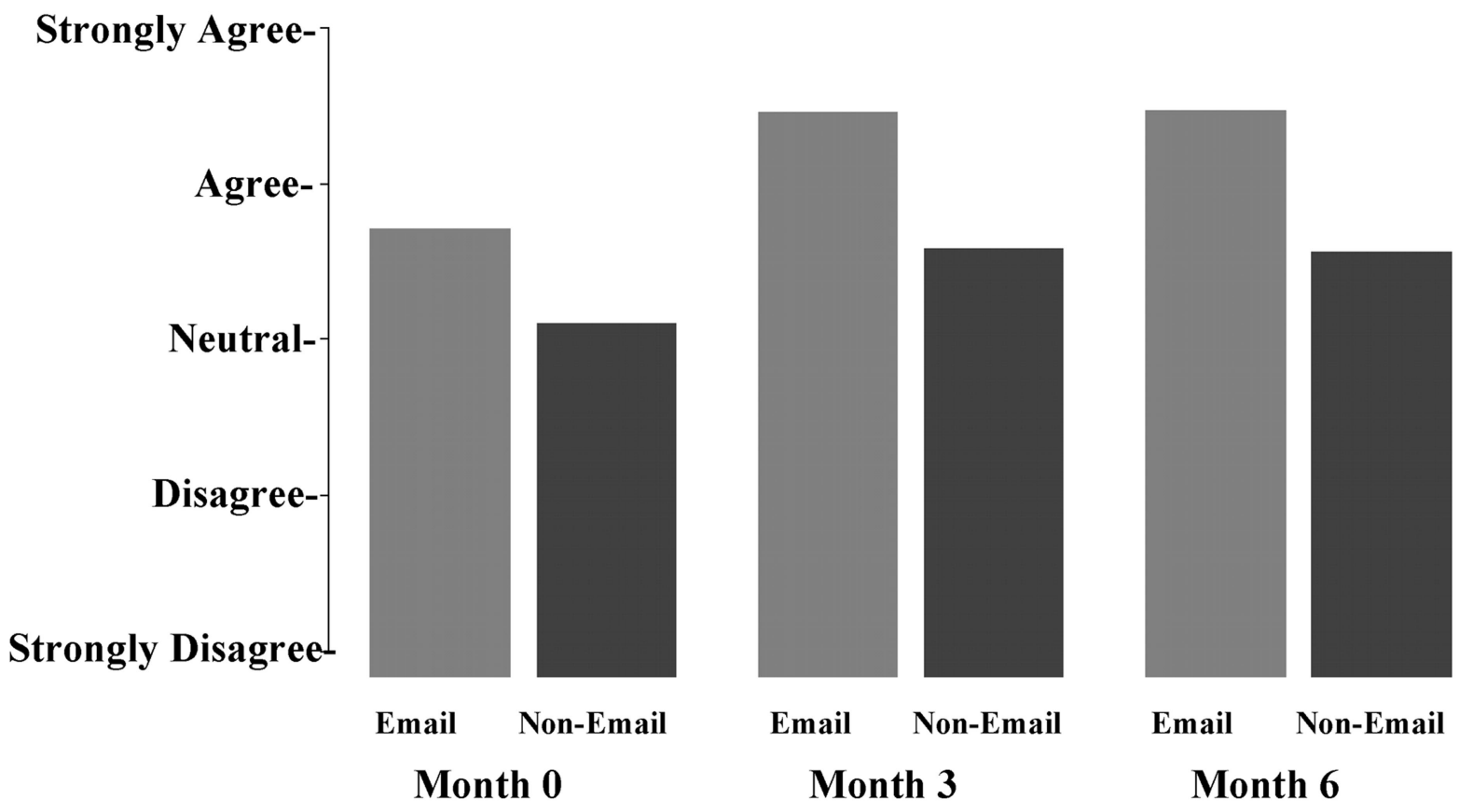

Figure 1. Patient satisfaction with the convenience of contacting doctor $(P<.0001)$. 
Table 4. Categories and Response Time of Messages

\begin{tabular}{|c|c|c|c|c|}
\hline & \multicolumn{2}{|c|}{ E-mail } & \multicolumn{2}{|c|}{ Phone } \\
\hline & $\mathrm{N}$ & $\%$ & $\mathrm{~N}$ & $\%$ \\
\hline Categories & \multicolumn{2}{|c|}{$(\mathrm{N}=299)$} & \multicolumn{2}{|c|}{$(\mathrm{N}=732)$} \\
\hline Informational & 95 & 32 & 37 & 5 \\
\hline Medical condition/consult & 93 & 31 & 199 & 27 \\
\hline Medication & 48 & 16 & 145 & 20 \\
\hline Administrative & 43 & 14.3 & 270 & 37 \\
\hline Test results & 20 & 6.7 & 81 & 11 \\
\hline Response Time & \multicolumn{2}{|c|}{$(\mathrm{N}=180)$} & \multicolumn{2}{|c|}{$(\mathrm{N}=340)$} \\
\hline Same day & 68 & 38 & 284 & 83.5 \\
\hline 1 day & 53 & 29.4 & 44 & 13 \\
\hline 2 days & 28 & 15.6 & 6 & 1.8 \\
\hline 3 days & 13 & 7 & 5 & 1.55 \\
\hline 4 days & 18 & 10 & 1 & 0.3 \\
\hline
\end{tabular}

$43(14 \%)$ administrative, and $20(6.7 \%)$ on test results.

\section{Response Time}

Of all the completed messages, 180 e-mail messages and 340 phone messages had sufficient data to calculate the time it took for the messages to be addressed by the physicians. Most phone messages (284 [83.5\%]) were answered in the same day. The response time was longer with e-mail; 68 (38\%) were answered in the same day, $53(29 \%)$ in 1 day, and $28(15.5 \%)$ in 2 days (Table 4). This may be the result of several factors. It is the practice's policy to address phone messages from patients the same day. Phone messages in general are more acute in nature, requiring more urgent attention. There is no policy on e-mail response time because it is not the usual mode of communication for the practice. Patients in the study were advised to use e-mail for only nonurgent messages and that a reply might take 2 to 3 working days. Because there was a separate account for patient e-mail, one physician experienced some difficulties remembering to check that account for messages. In addition, it was not possible to access the account off-campus.

\section{Time Required to Address Messages}

During the same 3 selected weeks, the physicians also tracked the number of messages received and reported the time spent addressing messages (Table $3)$. There was great variation in the volume of messages reported by physicians: 15 to 103 per week in the e-mail group and 21 to 72 per week in the control group. Likewise, physicians differed in the time they took to address messages, from an average of 12 to 62 minutes per day and 2 to 5.5 minutes per message. This variation occurred in both the e-mail and control groups. All but 2 physicians had fewer messages in the third week of the study. Over the study period, 299 emails were received from patients in the e-mail group. Similar to

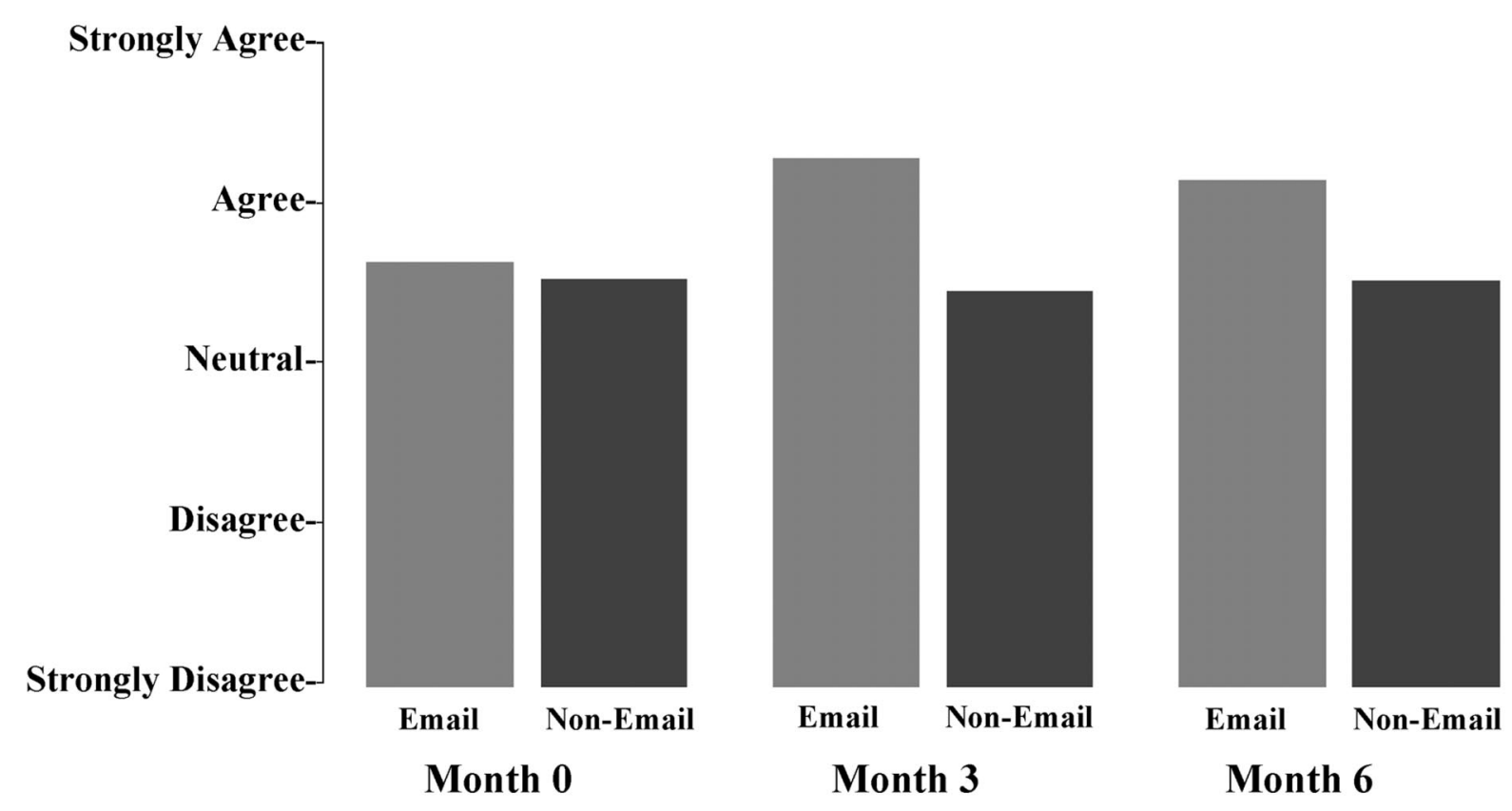

Figure 2. Patient satisfaction with the amount of time spent to contact doctor $(P<.0001)$. 
the non-e-mail messages, the volume of messages and the time spent addressing these messages differed from one physician to another. Based on self-reported data, most physicians took less time to address e-mail messages ( 1 to 3 minutes per message).

\section{Health Information Web Site}

Once informed of the http://www.familydoctor.org web site, $97 \%$ of the patients visited the site at least once. In the beginning of the study, most of the patients found the web site very useful, but nearly $50 \%$ rated it only somewhat useful by the end of the study.

\section{Preferences in E-Mail Communication}

At the conclusion of the study, all patients and physicians were asked, "Should patients be able to e-mail their doctors?" All patients in the e-mail group and $97 \%$ in the non-e-mail group responded yes to this question. The physicians were less uniform in their answers. All 4 physicians in the e-mail group, but only 2 of the 4 in the non-e-mail group, answered affirmatively. Most patients in the study would like to e-mail physicians; $90 \%$ in the e-mail group and $86 \%$ in the non-e-mail group would use it for prescription refills, and $39 \%$ in the e-mail group and $19 \%$ in the non-e-mail group would like to use it for scheduling appointments.

\section{Comments from the Patients}

Of the written comments received on the questionnaires, $40 \%$ (33 of 83 ) were comments praising e-mail as a convenient and efficient method of communication. The patients enjoyed being able to give a quick update on their conditions to their physicians or ask questions regarding referrals. Eleven patients expressed frustration when calling the office, citing the long hold time and phone "tag." One patient in the non-e-mail group wrote a lengthy letter urging the institution to provide e-mail access for all patients. Only 2 patients expressed concern over privacy issues.

\section{Discussion}

In our study, e-mail communication was judged to be a convenient form of communication between the patient and the physician. Satisfaction for patients was improved, and satisfaction for physicians seemed to be improved, but no improvement could be confirmed through statistical analysis of the data. The volume of messages and time spent answering messages for the e-mail group of physicians was not increased. However, the physicians commented that if e-mail were to be offered to a larger group of patients, additional support staff would be required to effectively manage the e-mail messages from patients. A triage system similar to that used by Stanford Medical Group in Palo Alto, California, where a staff member would route email to the appropriate person could help reduce the time burden on the physicians. ${ }^{16}$

Table 5 lists some important guidelines for e-mail communication between physician and patient. E-mail communication is ideal for short questions, brief updates, follow-ups, or clarification of instructions. It is not intended to replace the office visit. Issues that are complex, contain uncertainty, or would require negotiation should be addressed face-to-face in the office. To avoid legal and liability complications, an existent patient-physician relationship should be in place before offering advice via e-mail. With the Health Insurance Portability and Accountability Act (HIPAA) regulation, extra diligence is required to insure privacy. Before using e-mail to exchange information, physicians must obtain written informed consent from patients. Patients need to understand that e-mail communication is nonsecure and confidentiality cannot be guaranteed. E-mail should not be used for urgent or sensitive matters. Sands and others ${ }^{12,23}$ have provided useful guidelines for the appropriate use of e-mail. Since the conclusion of the study in July 2002, the Penn State Hershey Medical Center has issued a set of updated guidelines for e-mail communication with patients based on current national guidelines. The Penn State Hershey Medical Center Patient's Guide to e-mail is accessible at http://www.hmc.psu.edu/visitors/ HIPAAemail.pdf.

One limitation of this study is that neither physicians (who were placed in groups by the principal investigator to maintain a balance in physician characteristics) nor patients (who were assigned to their respective physician's group to maintain the doctor-patient relationship) were randomized, thereby creating uncertainty regarding the effects of the intervention. The small sample size of 8 physicians limited the potential for yielding statistically significant data. The patients were from a 
Establish turnaround time for messages.

Inform patients of the appropriate usage of e-mail.

Do not use e-mail for urgent matters or medical emergencies (such as chest pain, shortness of breath); instead call 911 or the office.

Do not use e-mail for sensitive matters (HIV, mental health issues, etc)

E-mail is best suited for brief communications. Office appointments are more appropriate for more complex issues.

E-mail communication is not a substitute for medical examination.

Put the type of transaction (such as prescription refill, referral, medical advice, etc) on the subject line.

Include name and patient identification number in the body of the message.

If a reply is needed before an e-mail is received from the physician, call the office.

Inform patients of privacy issues

The potential risk of the e-mail being read by a hacker or patient employer if patient is using e-mail at work..

The e-mail will be included as part of the medical record.

Office staff may handle the message.

Establish with whom and under what circumstances the physician may share the patient's e-mail, such as consulting another physician. (When consulting another physician by e-mail, consider omitting the patient's name and e-mail address).

Patient's e-mail address will not be used for marketing purposes.

Use automatic reply to acknowledge the receipt of messages.

Use "out-of-the-office" automatic reply and instruct patients on whom to call for assistance

Request patients to reply and confirm the receipt of the physician's message, especially important messages.

Use professional language, avoiding anger, sarcasm, or harsh criticism.

Develop archival and retrieval mechanisms.

Use the blind copy feature when sending group mailings to maintain recipients' privacy.

Develop a patient-physician agreement and informed consent for the use of e-mail, including the above guidelines. This should be discussed and documented in the patient's medical record.

university hospital-affiliated family practice office and were well-educated and Internet-savvy; therefore, the results may not be generalizable to other office settings and patient populations. The control group reported a higher rate of Internet use than the e-mail group (Table 2). The significance of this is unclear. The utility of the health information web site was modest, with declining interest and rating of the site over time. It is not known whether this is a reflection of the quality of the web site or is a typical pattern of use for web resources. More data are needed in this area.

Most e-mail messages from this study were for updates on conditions (32\%), short medical consultations (31\%), and questions related to medications $(16 \%)$. These types of information allow the physicians to manage the patients' medical problems beyond the office visit. By improving access to care and communication between patients and physicians, e-mail has the potential to help prevent medical errors. For example, with the ease of e-mail communication, patients may be more likely to report potential medication side effects before the next office visit, adding to medication safety. Coupled with a well-developed patient education web site, e-mail has the potential to improve patient education and improve management of diseases. In this study, the amount of time used to answer messages from patients was not increased, suggesting that potentially improved access by e-mail does not cause undue burden on the physician or practice.

E-mail is a widely used mode of communication. As we move toward using an electronic medical records system, e-mail would be a useful component. The medical field needs to define appropriate uses for this communication, develop standards and guidelines, ensure privacy and security, and assess and address issues related to compensation for service and legal and ethical implications. After taking the appropriate measures to address these important concerns, e-mail holds enormous potential as a practice tool to enhance health care delivery, as well as the health outcomes of patients.

We thank Connie Weirich and Stacey Haak, administrative assistants at Penn State College of Medicine, for their excellence in data collection and manuscript preparation. 


\section{References}

1. Spielberg AR. On call and online: sociohistorical, legal, and ethical implications of e-mail for the patient-physician relationship. JAMA 1998;280:1353-9.

2. Kassirer JP. Patients, physicians, and the internet. Health Aff (Millwood) 2000;19:115-23.

3. Liederman EM, Morefield CS. Web messaging: A new tool for patient-physician communication. J Am Med Inform Assoc 2003;10:260-70.

4. Pal B. Email contact between doctor and patient. BMJ 1999;318:1428-30.

5. Baker L, Wagner TH, Singer S, Bundorf MK. Use of the internet and e-mail for health care information: result from a national survey. JAMA 2003;289: 2400-6.

6. Neill RA, Mainous AG, Clark JR, Hagen MD. The utility of electronic mail as a medium for patientphysician communication. Arch Fam Med 1994;3: $268-71$.

7. Moyer CA, Stern DT, Dobias KS, Cox DT, Katz SJ. Bridging the electronic divide: patient and provider perspectives on e-mail communication in primary care. Am J Manag Care 2002;8:427-33.

8. Hobbs J, Wald J, Jagannath YS, et al. Opportunities to enhance patient and physician e-mail contact. Int J Med Inf 2003;70:1-9.

9. Couchman GR, Forjuoh SN, Rascoe TG. E-mail communications in family practice: what do patients expect? J Fam Pract 2001;50:414-18.

10. Eysenbach G, Diepgen TL. Responses to unsolicited patient e-mail requests for medical advice on the World Wide Web. JAMA 1998;280:1333-5.

11. Lewers DT. Guidelines for patient-physician electronic mail [monograph on the Internet]. Chicago: American Medical Association; 2000 [cited 2004 Dec 23]. Available from: http://www.ama-assn.org/ meetings/ public/annual00/reports/bot/bot2a00.rtf.

12. Sands DZ. Guidelines for the use of patient-centered e-mail [monograph on the Internet]. Waltham (MA): Massachusetts Health Data Consortium [cited 2004 Dec 23]. Available at: http://www.mahealthdata.org/data/ library/guidefiles/1999_PatientCtrdEmailGdlns-Sands. pdf.
13. Bauchner H, Adams W, Burstin H. You've got mail: issues in communicating with patients and their families by e-mail. Pediatrics 2002;109:954-6.

14. Green L. A better way to keep in touch with patients. Med Econ 1996;73:153-6.

15. Pallen M. Electronic mail. BMJ 1995;311:1487-90.

16. Taylor K. The clinical email explosion. Physician Exec 2000;26:40-5.

17. DeVille K, Fitzpatrick J. Ready or not, here it comes: the legal, ethical, and clinical implications of e-mail communications. Semin Pediatr Surg 2002;9:24-34.

18. Mandl KD, Kohane IS, Brandt AM. Electronic patient-physician communication: problems and promise. Ann Intern Med 1998;129:495-500.

19. Fridsma DB, Ford P, Altman R. A survey of patient access to electronic mail: attitudes, barriers, and opportunities [monograph on the Internet]. Stanford (CA): Stanford University School of Medicine; 1994 [cited 2004 Dec 23]. Available from: http://smi-web.stanford.edu/pubs/SMI_ Reports/SMI-94-0524.pdf

20. Ferguson T. A guided tour of self-help cyberspace. [monograph on the Internet]. Rockville (MD): Office of Disease Prevention and Health Promotion, Office of Public Health and Science, Office of the Secretary, US Department of Health and Human Services; 1996 [cited 2004 Dec 23]. Available from: http://odphp.osophs.dhhs.gov/confrnce/partnr96/ summary.htm

21. Nelson R, Stewart P. Use of electronic mail as a clinical tool. Healthc Inf Manage 1994;8:33-6

22. Borowitz SM, Wyatt JC. The origin, content, and workload of e-mail consultations. JAMA 1998;280: 1321-4.

23. Kane B, Sands DZ. Guidelines for the clinical use of electronic mail with patients. J Am Med Inform Assoc 1998;5:1-15.

24. Bergeron B. E-mail: a realistic conduit for patientdoctor communications? J Med Pract Manage 2000; $15: 208-10$.

25. Engstrom P. Can you afford not to travel the Internet? Med Econ 1996;73:172-4, 176, 180-1 passim.

26. Scherger JE. E-mail-enhanced relationships: getting back to basics. Hippocrates (Sausalito) 1999;13:7-8. 